NBER WORKING PAPER SERIES

SOME INEFFICIENCY IMPLICATIONS OF GENERATIONAL, POLITICS AND EXCHANGE

Laurence J. Kotlikoff

Robert W. Rosenthal

Working Paper No. 3354

NATIONAL BUREAU OF ECONOMIC RESEARCH

1050 Massachusetts Avenue

Cambridge, MA 02138

May 1990

Financial support from the National Institute of Aging under grant \#NIA-AG05842 and from the National Science Foundation under grant \#SES-8808362 is gratefully acknowledged. This paper is part of NBER's research programs in Aging and Taxation. Any opinions expressed are those of the authors and not those of the National Bureau of Economic Research. 
NBER Working Paper \#3354

May 1990

\section{SOME INEFFICIENCY IMPLICATIONS OF GENERATIONAL POLITICS AND EXCHANGE}

\section{ABSTRACT}

Generational selfishness is a central assumption in the vast 1 iterature on the life cycle model. Much of this literature deals with the impact of alternative government policies in light of self-interested generational behavior. Surprisingly, the cholces of governments in virtually all of these analyses are assumed to be independent of the preferences of the selfish generations these governments presumably represent. We address this anomaly by modeling each generation as having a government that strictly represents its interests. Such selfish generational governments will potentially distort the economy along a number of dimensions. We consider two types of Inefficiencies that have received little or no attention in the literature. The first is the monopolization of factor supplies, and the second is the under- or overprovision of durable public goods. We demonstrate that selfish generations may place sizable marginal taxes on their factor supplies in order to monopolize their factor markets. We also show that selfish generations will provide inefficient levels of durable public goods both at the local and national levels. Finally, we demonstrate that generational inefficiencles can arise even in models of cooperative bargaining because of the first-mover advantage of earlier generations.

Laurence J. Kotlikoff

Department of Economics

Boston University

270 Bay State Road

Boston, MA 02215
Robert W. Rosenthal

Department of Economics

Boston University

270 Bay State Road

Boston, MA 02215 
In the absence of intergenerational altruism one would expect each generation to act In its self interest vis-a-vis other generations. For example, one would expect current generations to expropriate as much as possible from future generations. This seems likely even if the membership of each generation is heterogeneous, at least insofar as generational issues are at stake.

While the selfish pursult of generational objectives would seem the only viable policy for a representative (of the living) government, the literature on intergenerational fiscal policy (e.g.; Summers (1981]) has, with rare exceptions (e.g., Kotlikoff, Persson, and Svensson (1988)), ignored this point and modeled government as having its own arbitrary objectives. Our paper addresses this anomaly by considering governments that are concerned solely with their generations' interests. Specifically, we assume that each generation has its own representative government. Each generation's government can, within certain limits, regulate the economic affairs of its members and bargain with other generations, but ft cannot unilaterally expropriate from other generations.

The notion of generation-specific governments may seem hard to reconcile with observed political institutions, but the competing power of different generations may well underlie actual political decisions. ${ }^{1}$ In any case, our purpose is to expose the kinds of inefficiencles that can result from

\footnotetext{
In the U.S. the elderly, at least, are viewed as a powerful and active political block. The AARP, the American Association of Retired Persons, appears to have near veto power on social security legislation. Also, a new group, AGE, Americans for Generational Equity, has arisen to look out for the welfare of the young.
} 
generationally self-interested behavior, and a model of autonomous generations seems a potentlally useful means toward that end.

Research on Inefficlencles arising from the combination of generational selfishness and the sequential nature of generational interactions has a long tradition In economics beginning with Samuelson's (1958) consumption-loan model. This paper extends that literature by considering two additional efficiency problems. The first is the prospect of factor monopolization by successive generations. The second is the prospect of inefficlent provision of durable public goods. In addition to considering these issues, the paper demonstrates that cooperative bargaining by coexisting generations is not, in general, enough to overcome such Inefficlencles.

In the simple, two-factor model of factor monopolization analyzed in Section I, we show that each generation has an Incentive to restrict its supply of labor when young and Its supply of capltal when old (its saving when young) In order to raise the respective market returns to these factors. The government of each generation Implements such factor monopolizations by placing distortionary taxes on Its members' supplies of labor and savings. The model's utility and production functions are Cobb-Douglas. Given these functions and realistic parameter cholces, the equilibrium wage taxes and capital-Income taxes turn out to be quite high; indeed, they are high enough to account for the level of distortionary wage and capital-income taxes in the U.S. Our factor-monopolization explanation for distortionary taxation is obviously different from the major alternative explanation in the literature provided by Mirrless (1971) and Sadka (1976), namely that governments use diatortlonary taxes to help sort taxpayers of differing, but unobserved, characteristics. 
In the analysis of nonexcludable durable public goods (bads) presented in Section II, we show that changes in asset prices associated with the provision of public goods-capitalization effects-can partly, fully, or more than fully offset the incentives of early generations to underprovide (overprovide) public goods (bads). The capitalization effect we consider is associated with the sale of land from one generation to the next. If the level of the public good (bad) positively (negatively) affects the marginal utility of owning land or housing, early generations will realize that increased provision of the public good will raise the market values of their properties. In the case of local durable public goods, capitalization incentives for providing these goods can arise even if the level of the public good does not affect the marginal utility of land. The reason is that, other things equal, a locality that provides more durable public goods will be more attractive to new residents (in our model new generations), and this added attraction will be reflected in the locality's value of land. While the competition between localities adds an additional element to the analysis, the special conditions under which the provision of durable public goods is efficient are identical In the cases of local and national (nonlocal) durable public goods.

In our models of factor monopolization and public goods provision, the governments representing the respective generations play noncooperatively; 1.e., It is assumed that there is no mechanism through which they can make binding agreements with each other. One might ask whether the inefficiencies in these games are due solely to the noncooperative rules of play. In the third section of the paper we present a simple model in which an older generation, which lives in periods 1 and 2 , and a younger generation, which lives only in period 2, bargain cooperatively (1.e., with the ability to establish binding contracts) in period 2. Notwithstanding their period 2 
cooperation, the older generation is able to "get the beat" on the younger generation in 1 ts first period of 11fe. "Getting the beat" in this model gives the older generation a better perlod-2 bargalning position, but also leads to an Inefficlent solution; no matter what efficlent, Individuallyrational bargalning solution is used in perlod two, as long as it is correctly forecast in period one, the resulting two-perlod consumption program is not Pareto-optimal among the feasible allocations for the two-period economy. In other words, because the two generations cannot bargain before the firstperiod consumption occurs, an inefficlency results. This Inefficiency is solely due to the lack of synchronicity of the generations and therefore seems inevitable in any intergenerational setting.

In the final section, IV, we conclude the paper with some remarks about the realism of generational models of government.
\end{abstract}

I. Factor Monopolization by Successive Generations

In this section we assume that each generation's government taxes its members' labor and capital incomes, but returns the recelpts from these taxes to them In a lump sum. These distortionary taxes reduce each generation's supplies of productive factors, thereby ralsing the market return to these factors.

The framework is an infinite-horlzon, overlapping-generations model. We assume zero population growth, so that the number of young and old are equal at each point in time. All individuals within a generation are identical and selfish, In that each cares only about his own consumption and lelsure. The members of each generation ilve for two perlods. They supply labor when young and capital (thelr accumulated savings) when old. The utility function 
underlying these supply decisions is Cobb-Douglas in consumption when young, consumption when o1d, and leisure when young.

When each new generation arrives on the scene, its government, acting in the interest of its members, announces a first-period labor-income tax and a second-period tax on capital ineome. Given these taxes, the individual members of each generation choose how much to work and consume when young and how wuch to save (invest) for old age. There are no bequests, so the old consume the entire return on their savings.

Output at any point in time is produced according to a Cobb-Douglas function of capital supplied by the old and labor supplied by the contemporaneous young. The pre-tax returns earned by these factor supplies are determined in competitive factor markets. Hence; while their governments act strategically in setting tax rates, individuals in each generation simply optimize subject to their after-tax budget constraints. This framework captures the notion that each generation's government can collect taxes on factor incomes, but cannot directly control any individual member's sale of factors on the market.

Since each generation's supplies of labor when young and capital when old are effectively determined by decisions made when the generation is young, the government of each generation makes its moves when the generation is young. Hence, the old generation's government does not act strategically; and the old generation passively supplies all its accumulated capital to the production sector and earns the market-deterwined return. The young generation, however, needs to consider how its second-period supply of capital will influence the supply of labor by the next generation. Thus, each new young generation finds itself moving first in a subgame that it plays with the next generation and, indirectly, with all other future generations. 
In setting its compensated taxes each government can effectively induce its members to choose the point on their individual budget constraints that the govermment desires. This fact permits us to simplify the analysis by having the government choose directly the values of labor supply and consumption that maximize its generation's utility, taking into account the equilibrium effect on future generations. This planner's problem differs, however, from utility maximization by a representative individual because the government planner takes into account the effect of its cholces on factor prices. We show later how the solution to the planning problem can be decentralized through an appropriate set of proportional (and hence marginal) taxes on labor and capital income which are rebated in a lump sum at the time they are paid.

The utility of the typical member of the generation that is young at time $t, U_{t}$, is given by:

$$
u_{t}=c_{y t}^{a} c_{o t+1^{2}}^{{ }^{1-a-b}}
$$

where $C_{y t}, C_{o t+I}$, and $2_{t}$ are, respectively, consumption of the young at time $t$, consumption of the old at time $t+1$, and leisure of the young at time $t$. The budget constraining the present value of consumption of the representative member of generation $t$ is:

$$
c_{y t}+c_{o t+1} R_{t+1}^{-1}-w_{t}\left(1-\ell_{t}\right)
$$

In (2) $R_{t+1}$ and $W_{t}$ stand, respectively, for the rental rates on capital in period $t+1$ and labor in period $t$. We assume 100 percent depreclation of capital during production; hence, $C_{o t+1}$ in (2) is divided by $R_{t+1}$ and not by $1+R_{t+1}$. The price of the consumption good at each point in time is normalized 
to unity. Each individual is endowed with one unit of time when young; hence, $1-\ell_{t}$ equals the individual's supply of labor.

Output per unit of labor at time $t, y_{t}$, is given by the Cobb-Douglas form $y_{t}-k_{t}^{\beta}$, where $k_{t}$ stands for capital per unit of labor and where $\beta$ is constant over time with $0<\beta<1$. Competition in factor markets ensures that marginal products of labor and capital equal their respective factor rentals, hence:

$$
\begin{aligned}
& \mathrm{w}_{\mathrm{t}}=(1-\beta) \mathrm{k}_{\mathrm{t}}^{\beta} \\
& \mathrm{R}_{\mathrm{t}}=\beta \mathrm{k}_{\mathrm{t}}^{\beta-1} .
\end{aligned}
$$

In choosing $l_{t}$, generation $t$ 's government takes into account that $w_{t}$ depends on $l_{t}$, since $w_{t}$ depends on $k_{t}-k_{t} /\left(1-l_{t}\right)$, where $k_{t}$ stands for capital per old person at time $t$. In choosing $C_{y t}$ as well as $l_{t}$, generation $t$ 's govermment also takes into account that $R_{t+1}$ depends on $k_{t+1}-k_{t+1} /\left(1-l_{t+1}\right)-$ $\left[W_{t}\left(1-l_{t}\right)-c_{y t}\right] /\left(1-l_{t+1}\right)$. The last equality reflects the fact that capital per old person at $t$ ime $t+1$ equals the saving done when young at $t$ ime $t$. Rewriting $W_{t}$ and $R_{t+1}$ to reflect their dependencies on $C_{y t}$ and $\ell_{t} y i e l d s$ :

$$
\begin{aligned}
& W_{t}=(1-\beta) k_{t}^{\beta}=(1-\beta)\left[\frac{\mathrm{K}_{t}}{1-l_{t}}\right]^{\beta} \\
& R_{t+1}-\beta k_{t+1}^{\beta-1}-\beta\left[\frac{\mathrm{K}_{t+1}}{1-\ell}\right]^{\beta-1}-\beta\left[\frac{(1-\beta)\left[\frac{\mathrm{K}_{t}}{1-\ell}\right]^{\beta}\left(1-\ell_{t}\right)-\mathrm{C}_{\mathrm{yt}}}{1-l_{t+1}}\right]^{\beta-1} .
\end{aligned}
$$

We can now state the planning problem of the government of generation $t$ : choose $C_{y t}, C_{o t+1}$, and $l_{t}$ to maximize (1) subject to (2) and ( $\left.3^{\prime}\right)$. In this 
maximization generation $t$, whose members are young at time $t$, takes as given $K_{t}$, the capital supplied by the old at time $t$.

In addition to taking account of the dependency of $W_{t}$ on $l_{t}$ and of $R_{t+1}$ on $l_{t}$ and $C_{y t}$, generation $t$ 's government must consider how its choices of these variables will influence $\left(1-l_{t+1}\right)$, the time-(t+1) labor supply chosen by generation $t+1$. We hypothesize that since $K_{t+1}$ summarizes all relevant Information at $t$ ime $t+1$, if $\ell_{t+1}$ depends on $\ell_{t}$ and $C_{y t}$, it depends on them only through their effect on $k_{t+1}$. We therefore study only subgame-perfect equilibria in which strategic actions at $t$ can depend on the history of play only through $K_{t}$ - so that punishments, for example, are ruled out. In the derivation of the optimal choices of $\ell_{t}$ and $C_{y t}$ we further hypothesize that the solution involves $\mathrm{d}_{s} / \mathrm{dK}_{\mathrm{s}}-0$ for all $s>t$. We then verify that this hypothesis is consistent by showing that it implies $\mathrm{d}_{t} / \mathrm{dK}_{t}-0$. Both of these hypotheses serve to focus attention on what we believe to be the interesting equilibrium. Other equilibria can be expected to exist as well.

The maximization with respect to $C_{y t}, C_{o t+l}$, and $l_{t}$ of (1) subject to (2) and (3') leads to the following first-order conditions:

$$
\frac{a C_{o t+1}}{b C_{y t}}-R_{t+1}(1-(1-\beta))
$$

$$
\frac{C_{y t}}{a l_{t}}-W_{t}(1-\beta)
$$

Equations (2), (4), and (5) can be solved for the optimal values of $C_{y t}$, $C_{o t+1}$, and $\ell_{t}$ which are given, respectively, in (6), (7), and (8): 


$$
c_{y t}=w_{t} \frac{a(1-\beta)}{1+(1-\beta)(a+b \beta)}
$$

$$
c_{o t+1}-w_{t} R_{t+1} \frac{b \beta(1-\beta)}{1+(1-\beta)(a+b \beta)}
$$

$$
\ell_{t}-\frac{1}{1+(1-\beta)(a+b \beta)} \text {. }
$$

From (8) we verify that $d \ell_{t} / d k_{t}=0$.

This solution can be decentralized with the government of generation $t$ instituting a wage tax at rate $\beta$, a capital income tax at rate $1-\beta$, a first period lump-sum payment $\mathrm{M}_{\text {yt }}$ equal to $w_{t}\left(1-l_{t}\right) \beta$, and a second period lump-sum payment $M_{o t+1}$ equal to $\left(W_{t}-l_{t}\right) R_{t+1}(1-\beta)$. The individual's budget constraint in this case is given by:

$$
C_{y t}+C_{o t+1}\left(R_{t+1} \beta\right)^{-1}-w_{t}(1-\beta)\left(1-\ell_{t}\right)+M_{y t}+M_{o t+1}\left(R_{t+1} \beta\right)^{-1} .
$$

Taking $R_{t+1}$, $W_{t}$. Myt and $M_{o t+1}$ as given, the individual's maximization of (1) subject to (9), leads to the first-order conditions (4) and (5). Since (9) is equivalent to (2) given the definitions of $M_{y t}$ and $M_{o t+1}$, the individual's demands for $C_{y t}, C_{o t+1}$, and $l_{t}$ are those in (6)-(8).

In the U.S. capital's share of net national product is roughly 25 percent. 2 If we use that value for $\beta$ the solution calls for a 25 percent tax on labor income and a 75 percent tax on capital income. The intuition behind this solution is that the first-order conditions involve the elasticity of $R_{t+1}$ with respect to $k_{t+1}$ and the elasticity of $w_{t}$ with respect to $k_{t}$. The

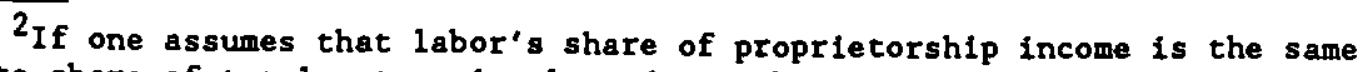
as its share of total net national product, then labor's 1989 share of net national product is 72.6 percent. Source: Economic Report of the President.
1990 . 
former elasticity equals $\beta-1$, while the latter elasticity equals $\beta$. Since the interest rate is more elastic with respect to changes in relative factor supplies than is the wage, it follows that the optimum includes a larger distortion of saving than of labor supply.

We next compare (6) through (B) with their counterparts (10), (11), and (12) below, which are the equilibrium values when no strategic behavior on the part of generations is assumed.

$$
\begin{aligned}
& c_{y t}=w_{t} \frac{a}{1+a+b} \\
& c_{o t+1}=w_{t} R_{t+1} \frac{b}{1+a+b} \\
& l_{t}=\frac{1}{1+a+b} .
\end{aligned}
$$

Since $\beta<1, \ell_{t}$ is larger when generations are strategic; hence, there is a monopolization (reduction) of labor supply. Under strategic behavior saving by the young at time $t, w_{t}\left(1-\ell_{t}\right)-C_{y t}$, equals $w_{t}(1-\beta) \beta b /[1+(1-\beta)(a+b \beta)]$, while it equals $w_{t} b /(1+a+b)$ with no strategic behavior. It is easy to see that the former quantity is less than the latter quantity. Thus, there is also a monopolization of the supply of capital. While the supplies of labor and capital are reduced by strategic behavior, consumption when young and old, $c_{y t}$ and $C_{o t+1}$, may be larger or smaller depending on parameter values.

To get an idea of the magnitude of factor aonopolization, suppose a-1, $b-2$, and $\beta-.25$. For these parameters saving by the young equals half their wages in the absence of monopolization. With monopolization saving by the young equals less than a fifth of their wages. In addition, the labor supplied by the young is alnost 25 percent swaller due to monopolization. 
While these results are based on our particular utility- and productionfunction assumptions, it appears that the strategic manipulation of factor supplles would arlse for virtually all nicely behaved preferences and production technologies. It appears unlikely, however, that one would be able to derive closed-form solutions with assumptions that are less specific than those made here. The reason is that in equilibrium $\mathrm{d} \ell_{t} / \mathrm{dk}_{t}$ is generally nonzero, and its value will depend on all future values of this derivative. Unless a consistent stationary pattern exists for these derlvatives, there is no hope for an explicit solution.

To summarize, our model of factor monopolization by successive generations delivers an explanation for distortionary taxation. The particular Cobb-Douglas example suggests that generational factor monopolization can account for quite high marglnal tax rates as well as capital income taxes in excess of labor income taxes.

\section{Inefficient Provision of Durable Public Goods}

One of government's presumed functions is to overcome the inefficlencles of laissez faize in the presence of economic externalitles-for example, the free-rider problem assoclated with public goods. Some nonexcludable public goods (such as highways) are durable enough to service multiple generations. But if successive govermments attend only to the selfish interests of their own generations and cannot force future generations to pay part of the cost of the public good, one might expect to observe an underprovision of durable public goods. A possible amellorating factor is that generations might be able to recoup their investments in durable public goods if such investments lead to higher values of land or other assets. Such asset capitalization might be of particular relevance in the case of durable local public goods 
since locational choice-the choice of where to buy or rent land and housingis influenced by the availability of local public goods.

In this section we explore two capitalization models. The first is a "national" model in which the durable public good is available to anyone owning land in the society. The second is a two-region model in which the durable public good is available only to individuals owning land in the region (locality). While the capitalization effects differ somewhat across the two models, both models suggest an underprovision of durable public goods unless there are strong utility complementarities between public goods and land. While there is an extra source of capitalization in the two-region model as compared with the national model, it turns out that there is underprovision (overprovision) at the symmetric equilibrium of the regional model if and only if there is underprovision (overprovision) at the equilibrium of the national model.

Stiglitz (1983) also examines the provision of local public goods in light of land-capitalization effects. His conclusion that land capitalization leads to an efficient provision of public goods hinges on his assumption that each locality takes the utility level offered by alternative localities as given. In contrast, we assume that each locality takes the level of taxation and therefore the level of the public good provided by other localities as given. Since in the simplest versions of local-public-goods models each region offers the same level of utility in equilibrium, each region knows that if it raises its utility level (attractiveness to new residents), the utility levels of all other regions, no matter how many and how large, adjust through the process of individuals "voting with their feet." Accordingly, in our model, we assume that each region takes the actions (tax rate and level of the public good) of the other region as given, rather than the utility level in 
the other region, and assumes that prices will adjust in response to its own strateglc move so as to equate utilities anew across the localities.

\section{A. The National Model}

To keep things as simple as possible, we assume that there are only two perlods and two generations. Only the early generation lives in the first period, while the two generations coexist in the second perlod. There are three goods: a public good, a private consumption good, and land. Each of the $n$ Identical members of the early generation is endowed with one unit of the private good and one unit of land. Private goods not consumed can be used to produce public goods in the first perlod only. The technology is simple; one unit of the private good is sufficient to generate one unit of the public good. The public good does not depreclate and is non-excludable. The private good is storable with no depreclation or appreciation across the two perlods.

To focus on the essential 1ssues, we assume that the members of the early generation gain no direct benefit from the public good, so that none will be provided absent some compensation mechanism. The utility function of the typical member of the early generation $15 u\left(c_{1}, c_{2}\right)-c_{1}+c_{2}$, where $c_{t}$ is consumption of the private good in perlod $t(t-1,2)$. In addition to any savings, second-perlod consumption comes from the sale of land to the later generation, whose $n$ Identical members are endowed only with one unit of the consumption good in the second period and whose utllity functions are given by $w(c, s, q)$, where $c$ is consumption of the private good, $s$ is the amount of land purchased, and $q$ is the quantity of public good that has been provided in the flrst period.

The land market is competitive: if the price of land relative to the private good is $p$, the typlcal second-generation member's budget constraint is 
ctps - 1, and the first-order condition for his utility maximization problem 1s

$$
-p w_{1}(1-s p, s, q)+w_{2}(1-s p, s, q)=0
$$

where subscripts indicate partial derivatives in (13) and below where obvious.

Land is assumed to be supplied inelastically (the first generation's government cannot strategically confiscate land to drive up its price); so at an interfor competitive equilibrium s-1 and

$$
p=\frac{w_{2}(1-p, 1, q)}{w_{1}(1-p, 1, q)}
$$

Recognizing the dependence of $p$ on $q$, the first generation's government can levy a tax of per capita on 1 ts members and use it to produce $n$ units of the public good. ${ }^{3}$ The budget constraint of each member of the first generation is then $c_{1}+c_{2}-1+p-+$. Since utility of the first generation also equals $c_{1}+c_{2}$, the government of the first generation chooses $r$ to maximize $1+p(r)-r$, where $p(r)$ is defined by (14) for $q-n r$. Thus the first-order condition for the provision of the durable public good in this problem is $d p / d r=1$, or

$$
-w_{1}^{2}+n w_{1} w_{23}-n w_{2} w_{13}+w_{2} w_{11}-w_{1} w_{21}-0
$$

Equation (15) may be compared with the efficiency (Samuelson's) condition

$$
-w_{1}+n w_{3}=0
$$

$$
\text { model. }
$$

${ }^{3}$ The second-generation's government is assumed to play no role in this 
Equations (15) and (16) are not the same, and, except in very special circumstances, the strategically-acting first-generation government will not supply an efficlent amount of the public good. For example, if the function w is separable in its three arguments, the price of land in (13) will not depend on the level of the public good; so the first generation will provide none of the public good (a corner solution so (15) does not hold). At the other extreme, we can have a corner solution with $r-1$ if the term $w_{23}$ is sufficiently large. Since $w_{23}$ does not appear in (16) it is not hard to construct examples in which equilibrium involves overprovision of the durable public good.

\section{B. The Regional Model}

Now suppose that there are two localities, $\alpha$ and $\beta$, each with a first generation of $n$ members as specified above, and suppose that the public good's benefits accrue only to those in the second generation (of size $2 n$ ) who live In the locality where it is provided. Second-generation members may purchase land and live in either locality, but not in both. Let $n_{\alpha}$ and $n_{\beta}$ stand, respectively, for the number of second-generation members locating in regions $\alpha$ and $\beta$; so $n_{\alpha}+n_{\beta}-2 n$. Let $s_{\alpha}$ stand for the amount of land purchased by a second-generation member locating in region $\alpha$. In equilibrium $s_{\alpha}-n / n_{\alpha}$. Hence, by anslogy with equation (13), the equilibrium prices $P_{\alpha}$ and $p_{\beta}$ of land in localities $\alpha$ and $\beta$, respectively, satisfy 


$$
\begin{gathered}
P_{\alpha}-\frac{w_{2}\left(1-\frac{n}{n_{\alpha}} P_{\alpha}, \frac{n}{\left.n_{\alpha}, n r_{\alpha}\right)}\right.}{w_{1}\left(1-\frac{n}{n_{\alpha}} P_{\alpha}, \frac{n}{n_{\alpha}}, n r_{\alpha}\right)} \\
P_{\beta}-\frac{w_{2}\left(1-\frac{n}{2 n-n_{\alpha}} P_{\beta}, \frac{n}{2 n-n_{\alpha}}, n r_{B}\right)}{w_{1}\left(1-\frac{n}{2 n-n_{\alpha}} P_{\beta} \cdot \frac{n}{2 n-n_{\alpha}}, n r_{B}\right)},
\end{gathered}
$$

where $r_{\alpha}$ and $r_{\beta}$ are the respective taxes. At an interior equilibrium the second-generation members must be indifferent between locating in either locality, hence,

$$
w\left(1-\frac{n}{n_{\alpha}} P_{\alpha} \cdot \frac{n}{n_{\alpha}}, n r_{\alpha}\right)-w\left(1-\frac{n}{2 n-n_{\alpha}} P_{\beta}, \frac{n}{2 n-n_{\alpha}}, n_{\beta}\right)
$$

Equations (17) and (18) implicitly define functions $p_{\alpha}-p^{\alpha}\left(n_{\alpha}, r_{\alpha}\right)$ and $\mathrm{P}_{\beta}-\mathrm{P}^{\beta}\left(\mathrm{n}_{\alpha},{ }^{r_{\beta}}\right)$. These can be substituted into equation (19), with the result being an expression for $n_{\alpha}$ as a function $n^{\alpha}\left(\tau_{\alpha},{ }_{\beta}\right)$ of the tax rates.

We now assume that the two first-generation governments choose their respective tax rates as simultaneous moves in a noncooperative game. Recall that the utility of the typical first-generation resident of region $A$ is $1+p_{\alpha}-r_{\alpha}-1+p^{\alpha}\left(n^{\alpha}\left(r_{\alpha}, r_{\beta}\right), r_{\alpha}\right)-r_{\alpha}$. Differentiating this expression with respect to the strategic variable $r_{\alpha}$ and equating to zero yields

$$
p_{1}^{\alpha} n_{1}^{\alpha}+p_{2}^{\alpha}-1 \text {. }
$$

A comparison of equations (20) and (16) Indicates that an interior symmetric equilibrium will be efficient only if the left-hand side of (20) equals $n w_{3}^{a} / w_{1}^{a}$. where $w_{1}^{a}$ stands for the the ith partial derivative of $w$ evaluated as in the left-hand side of (19). Differentiating (19) with respect to $r_{a}$, 
substituting (17) and (18) in the result, evaluating at the symmetric equilibrium where $n_{\alpha}-n$ and (19) holds, and simplifying yields ${ }^{4}$ :

$$
p_{1}^{\alpha} n_{1}^{\alpha}+p_{2}^{\alpha}-\frac{n w_{3}^{\alpha}}{w_{1}^{\alpha}}+p_{1}^{\beta} n_{1}^{\alpha} \text {. }
$$

Since the right-hand side of (21) differs generally from nwa $\frac{0}{3} / \frac{\pi}{1}$, the provision of durable local public goods will not, in general, satisfy the efficiency condition. Solving (21) for $\mathrm{n}_{1}^{\alpha}$ and substituting the resulting expression into (20) yields

$$
\frac{n w_{3}^{\alpha}}{w_{1}^{\alpha}}+p_{2}^{\alpha}-2
$$

using the fact that in the symmetric equilibrium $p_{1}^{\alpha}--p_{1}^{\beta}$. Note that if $\mathrm{p}_{2}^{\alpha}=\mathrm{nw} \frac{\alpha}{3} / w_{1}^{\alpha}$, we have from (22) that $n w_{3}^{\alpha} / w_{1}^{\alpha}-1$, which is the efficiency condition. But the conditions under which $\mathrm{p}_{2}^{\alpha}-\mathrm{n} w_{\frac{1}{3}} /$ w $\frac{\alpha}{1}$ are simply those required for efficiency in the national model. In addition underprovision (overprovision) occurs exactly under the same circumstances in both models.

Since (15) indicated no reason to expect efficient provision of the public good in the national model, there is no reason to expect efficient provision of the public good in the regional model. The regional model, however, appears to deliver more of the public good than the national model in certain interesting cases. Consider, for example, the case of separable utility. In this case $p_{2}^{\alpha}=0$ and, while there will be no public goods provided in the national model, a positive, but less than efficient level of the public good will be provided in the reglonal model.

\footnotetext{
"It is easy to see that this same expression arises regardless of the relative size of the two regions. Hence, even if one region is tiny relative to the rest of the country, this relationship will hold.
} 


\section{Inefficlencies in Intergenerational Bargaining}

So far, all the inefficlencies in this paper have been associated with equilibria of intergenerational noncooperative games. In this section we exhibit an inefficiency arising in the context of an intergenerational cooperative bargaining model. At first glance this seems paradoxical, since the solution concepts of cooperative-game theory typically assume Pareto optimality. The resolution of the seeming paradox is that al though the analysis assumes that the generations bargain to an efficient solution, this bargaining can only take place once the generations coexist. When one generation precedes another prior to an overlapping era, there are times before the existence of the later generation when the members of the earlier generation take actions that have economic consequences, and these economic consequences, in turn, affect the initial positions in the bargaining game. 5 Thus the earlier generation has incentives to take actions strategically before the bargaining begins so that it will be better positioned for the bargaining game, even though the strategic actions may cause an inefficiency. (In this sense, the inefficiency results from noncooperative aspects of the rules of the game.)

On one level, the result is no surprise; for instance, if the efficient allocations all involved the earlier generation investing in some durable public good, which it would not do by itself, the absence of the later generation during the efficient investment time period means that the earlier generation can extract no quid pro quo and therefore will not find it in its interest to undertake the investment. What is perhaps surprising is that the bargain.

\footnotetext{
${ }^{5}$ of course, if the generations do not overlap at all, they cannot ever
} 
same effect can be obtained without public goods, in fact without production at all. All that is necessary is an intertemporal consumption complementarity.

We exhibit a simple example in which all cooperative bargaining solutions (1.e., solutions for the Nash bargaining problem) satisfying minimal assumptions give rise to the inefficiency. There are two players (generations)-A and $B$. As in the previous section, player A lives for two perlods, while B lives only in the second period. There are two goods- $X$ and $Y$. A is endowed with one unit of good $X$ in the first period, any part of which can be consumed then, with the rest stored for consumption or exchange (or some of each) in the second period. B is endowed with one unit of good $Y$ (In the second period, of course), which can be consumed and/or exchanged then. Denoting $A$ 's consumption of $X$ in the two periods by $x_{1 A}$ and $x_{2 A}$, respectively, and $A^{\prime}$ 's consumption of $Y$ in the second period by $y_{A}$, we take $A^{\prime} s$ utility of consumption to be

$$
u_{A}\left(x_{1 A}, x_{2 A} \cdot y_{A}\right)-\left(x_{1 A} x_{2 A}\right)^{1 / 2}+y_{A} .
$$

B's utility for consumption is taken to be

$$
u_{B}\left(x_{B}, y_{B}\right)-x_{B}+y_{B} \text {, }
$$

where $x_{B}$ and $y_{B}$ are $B^{\prime} s$ consumption of $X$ and $Y$, respectively, in the second period. Feasibility requires

$$
x_{1 A}+x_{2 A}+x_{B}-1, y_{A}+y_{B}-1 \text {, and nonnegativity of all variables. }
$$

Individual rationality ex ante requires that the consumptions satisfy

$$
u_{A}\left(x_{1 A}, x_{2 A}, y_{A}\right) \geq 1 / 2 \text { and } u_{B}\left(x_{B}, y_{B}\right) \geq 1 \text {. }
$$


since $A$ can assure himself utility of $1 / 2$ by consuming the vector $(1 / 2,1 / 2,0)$ without trade, and $B$ can assure 1 by consuming $(0,1)$ without trade. The utilities that result from all the allocations that are both individually rational and ex ante Pareto optimal are $(2,2-z): 1 / 2 \leq z \leq 1)$ obtained by A consuming $Z \geq 1 / 2$ units of good $Y$ and $B$ consuming all of good $X$ and (1-z) units of good $Y$.

The bargaining game begins after $x_{1 A}$ is consumed, so fixing $x_{1 A}-\lambda$, the threat levels of utility in the bargaining game are $(\lambda(1-\lambda))^{1 / 2}$ and 1 , for the two players respectively, and the ex post individually-rational and Pareto optimal bargains are obtained by maximizing

$$
\left(\lambda x_{2 A}\right)^{1 / 2}+y_{A} \text { subject to }\left(1-y_{A}\right)+\left(1-\lambda-x_{2 A}\right)-\text { constant }
$$

and nonnegativity constraints. The solutions all involve

$$
x_{2 A}=\min \{\lambda / 4,1-\lambda\}
$$

If $\lambda-0$, the bargaining problem is simply one of sharing one unit of surplus, since Player A's threat level of utility is zero, Player B's is one, and the extra unit of surplus can be split unrestrictedly between them. All serious solutions to this Nash bargaining problem involve a $1 / 2-1 / 2$ split of the surplus, bringing Player A back to his ex-ante individual-rationality bound. If $\lambda>0$, any solution to the bargaining game is ex-ante inefficient, so it only remains to show that under any bargaining solution, Player $A$ is better off setting $\lambda>0$ and then bargaining rather than setting $\lambda-0$ and settling for the utility of $1 / 2$ he could have earned by Ignoring the later generation. of course, the optimal value of $\lambda$ for Player $A$ depends on the specific bargaining solution to be employed, but it is easy to see that by setting $\lambda-1 / 2$ player 
A guarantees that he recelves utility more than $1 / 2$ unless the bargaining solution is completely unresponsive to him. To see this, note that if $\lambda-1 / 2$ and $x_{2 A}$ is set to $1 / 8$ (see above) the sum of the two utilities is $1 / 4+3 / 8+1>3 / 2$. Since the threat utilities sum to $3 / 2(1 / 2$ and 1 , respectively), there is surplus to be shared, and, so long as A gets some of 1t (as all solutions to Nash's bargaining problem prescribe), the argument is complete.

One lesson from this example is that a potential ex ante inefficiency arises from the simple fact that all generations cannot be present at the beginning of time to bargain, or Indeed at any time in which there are efficlency gains to be had from coordinated action. A second lesson is that the coordinated actions can range from the falrly obvious case of production of a durable public good linked to a subsequent transfer as quid pro quo at one extreme, to the (perhaps) less obvious case of pure exchange when there are intertemporal consumption complementarities at another extreme.

IV. Conclusion

Th1s paper develops some implications of selfish generational behavior. Its message is pessimistic. In seeking their own advantages, generations are likely to monopolize their factor supplies, provide inefficlent levels of durable public goods, and act strategically in producing or consuming private goods. One can think of additional inefficlencies assoclated with the sequential nature of generational exchange, such as inefficlent risk sharing.

If the implications of representative generational government are pessimistic, are they realistic? After all, one does not observe separate elections for different age groups. We argue that the decisions made by observed political institutions should of ten mimic those that would be made by 
representatives of different generations. Consider, for example, the monopolization of factor supplies. If elected officials know that young constituent workers favor compensated wage and capital-income taxes and that their older constituents are indifferent to the perpetuation of such compensated taxes, they will, presumably, enact such taxes. Elected politicians might also emulate the behavior of generational governments in cases of conflict between different contemporaneous generations. If the elderly favor policy $x$, while the young favor policy $y$, and policy $z$ would be the equlibrium outcome determined with generational representation, a typical politician might choose policy $z$ because he realizes that any other choice of policy would lead to the emergence of candidates for his office appealing to particular age groups. Alternatively, fallure to adopt $z$ could lead the age group that fared less well than under policy $z$ to withdraw support for the politician.

One way out of generational inefficiencies of the sort considered here is to hypothesize an infinite horizon and an equilibrium in which generations punish their elders if the elders fail to provide a quid pro quo (or fail to punish an earlier generation for failing to provide a quid pro quo, or ...) as in Kotlikoff, Persson, and Svensson (1988). This seems implausible, somehow. Another way out is to assume that intergenerational altruism is built into the collective human psyche. While we certainly observe altruistic behavior in everyday life that seems almost instinctive (Frank [1988]), recent empirical research (e.g., Altonj1, Hayashi, and Kotlikoff [1989]) suggests that observed altruistic behavior is far from the Becker (1974)-Barro (1974) perfect intergenerational altruism needed to overcome the efficiency problems raised here. It seems likely therefore that the intergenerational inefficiencies described here arise to some degree. 
References

Altonj1, Joseph, Fumio Hayashi, and Laurence J. Kotlikoff, "Is the Extended Family Altruistically Linked?," NBER working paper, 1989.

Barro, Robert, "Are Government Bonds Net Wealth?," Journal of Political Economy vol. 82 (1974).

Becker, Gary, "A Theory of Social Interactions," Journal of Political Economy vol. 82 (1974).

Frank, Robert H., Passions Within Reason, New York, N.Y., W.W. Norton Company, Inc., 1988 .

Kotlikoff, Laurence J., Thorsten Persson, and Lars Svensson, "Soclal Contracts as Assets: A Possible Solution to the Time Consistency Problem, "Amertican Economic Review vol. 78 (1988).

Mirrless, James, "An Exploration in the Theory of Optimum Taxation," Review of Economic Studies, vol. 38 (1971).

Sadka, Efraim, "On Income Distribution, Incentive Effects, and Optimal Income Taxation," Review of Economic Studies, vol. 43 (1976).

Samuelson, Paul A., "An Exact Consumption-Loan Model With or Without the Social Contrivance of Money," Journal of Polftical Economy, vol. 66 (1958).

Stiglitz, Joseph E., "The Theory of Local Public Goods Twenty-Five Years After Tiebout: A Perspective," in Local Provision of Public Services: The Tlebout Model After Twenty-five Years, New York, N.Y.: Academic Press, 1983.

Summers, Lawrence H., "Capital Taxation and Capital Accumulation in a Life Cycle Growth Model," American Economic Review, vol. 71 (1981). 